\title{
(2) OPEN ACCESS \\ Lung Screen Uptake Trial: results from a single lung cancer screening round
}

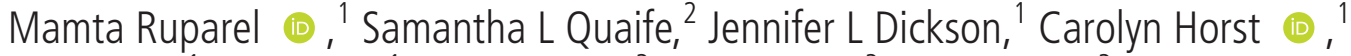 \\ Sophie Tisi, ${ }^{1}$ Helen Hall, ${ }^{1}$ Magali Taylor, ${ }^{3}$ Asia Ahmed, ${ }^{3}$ Penny Shaw, ${ }^{3}$ Stephen Burke, \\ May-Jan Soo, ${ }^{4}$ Arjun Nair, ${ }^{3}$ Anand Devaraj ${ }_{1}^{5}$ Karen Sennett, ${ }^{6}$ Stephen W Duffy, ${ }_{1}^{7}$ \\ Neal Navani (1) ${ }^{1,8}$ Angshu Bhowmik, ${ }^{9}$ David R Baldwin, ${ }^{10}$ Sam M Janes
}

\begin{abstract}
- Additional material is published online only. To view please visit the journal online (http://dx.doi.org/10.1136/ thoraxjnl-2020-214703)
\end{abstract}

For numbered affiliations see end of article.

\section{Correspondence to} Dr Sam M Janes, Lungs for Living Research Centre, UCL Respiratory, University College London, London WC1E 6JJ, UK s.janes@ucl.ac.uk

Received 24 February 2020 Revised 22 May 2020 Accepted 3 June 2020 Published Online First 5 August 2020

\section{Check for updates}

(C) Author(s) (or their employer(s)) 2020. Re-use permitted under CC BY. Published by BMJ.

To cite: Ruparel M, Quaife SL, Dickson JL, et al. Thorax 2020;75:908-912.

\section{ABSTRACT}

The Lung Screen Uptake Trial tested a novel invitation strategy to improve uptake and reduce socioeconomic and smoking-related inequalities in lung cancer screening (LCS) participation. It provides one of the first UK-based 'real-world' LCS cohorts. Of 2012 invited, 1058 (52.6\%) attended a 'lung health check'. 768/996 $(77.1 \%)$ in the present analysis underwent a low-dose CT scan. 92 (11.9\%) and 33 (4.3\%) participants had indeterminate pulmonary nodules requiring 3-month and 12-month surveillance, respectively; 36 lung cancers (4.7\%) were diagnosed (median follow-up: 1044 days). $72.2 \%$ of lung cancers were stage $\mathrm{I} / \mathrm{II}$ and $79.4 \%$ of non-small cell lung cancer had curative-intent treatment.

\section{INTRODUCTION}

Lung cancer screening (LCS) by low-dose CT (LDCT) has been repeatedly shown in clinical trials to reduce lung cancer mortality. ${ }^{1-3}$ The benefits of screening may be underestimated in these trials due to participants being younger, of higher socioeconomic position and disproportionately former rather than current smokers compared with the high-risk target population. The risk profile of the population enrolled determines the prevalence and stage of lung cancers, the false positive rate and the mortality benefit. Screening the highest risk quintiles can optimise the benefit-harm ratio while making LCS more equitable, efficient and costeffective. $^{45}$

Data from a prior UK-based 'real world' screening pilot in Manchester has shown compelling results with high levels of attendance by those from lower socioeconomic quintiles and radical treatment rates. ${ }^{6}$ Here we report the nodule and cancer outcomes from the Lung Screen Uptake Trial (LSUT).

\section{METHODS}

The LSUT methods and primary attendance results have been described previously ${ }^{78}$ and more detail is included in the online supplementary appendix. LSUT was a randomised controlled trial evaluating the impact of 'targeted, stepped and low burden' invitation materials on attendance of a 'lung health check' (LHC) appointment. Individuals aged 60 to 75 years, who had been recorded as 'current smokers' within the seven preceding years were sent an invitation letter from their usual general practice doctor inviting them to an LHC. Those attending were invited to participate in the study, and those meeting any of the following criteria were offered a single LDCT on the same day (or later if preferred): $\geq 30$ pack-years and if a former smoker had quit $\leq 15$ years ago, or a lung cancer risk of $\geq 1.51 \%$ or $\geq 2.5 \%$ as determined by the Prostate, Lung, Colorectal and Ovarian study or the Liverpool Lung Project models, respectively.

Self-reported demographics, smoking, family and medical history were recorded prospectively. Handheld pre-bronchodilator spirometry, height, weight and blood pressure were recorded. LDCT findings were evaluated and managed in accordance with the British Thoracic Society (BTS) 2015 guidelines for pulmonary nodules ${ }^{9}$ and the National Institute for Health and Care Excellence (NICE) guidelines for the diagnosis and management of lung cancer. ${ }^{10}$ Staging was carried out according to the $7^{\text {th }}$ edition TNM (tumour,node, metastases) classification system.

In the present study, we report the outcomes relating to LDCT scans with an indeterminate pulmonary nodule or suspected lung cancer. Other incidental finding outcomes have been reported elsewhere. ${ }^{11} 12$ Study participants with complete smoking and lung cancer risk data were included. Descriptive statistics were used to present the data pertaining to pulmonary nodules and lung cancer outcomes.

\section{RESULTS}

Of the $1058(52.6 \%)$ invitees $(n=2012)$ attending a LHC appointment between November 2015 and July 2017, 996 were included in the present analysis. A total of 895 participants were eligible for LDCT, though 36 were excluded due to prior CT of the chest in the past year, or an inability to lie flat and 91 participants declined or failed to attend the CT. An LDCT examination was completed by $768(77.1 \%)$ of the participants (figure 1). The demographic characteristics of the 996 participants included are presented in table 1 .

At the baseline LDCT scan, a total of $125 / 768$ participants had indeterminate pulmonary nodules requiring 3 -month $(\mathrm{n}=92(11.9 \%))$ or 12 -month $(n=33(4.3 \%))$ surveillance and a further $33(4.3 \%)$ were considered to have lesions suspicious for lung cancer that instigated referral to the local multidisciplinary meeting. The remaining 610 participants had a 'normal' scan or had non-malignant findings that have been discussed elsewhere. ${ }^{13} 14$ After a median follow-up of 1044 days, a total of 


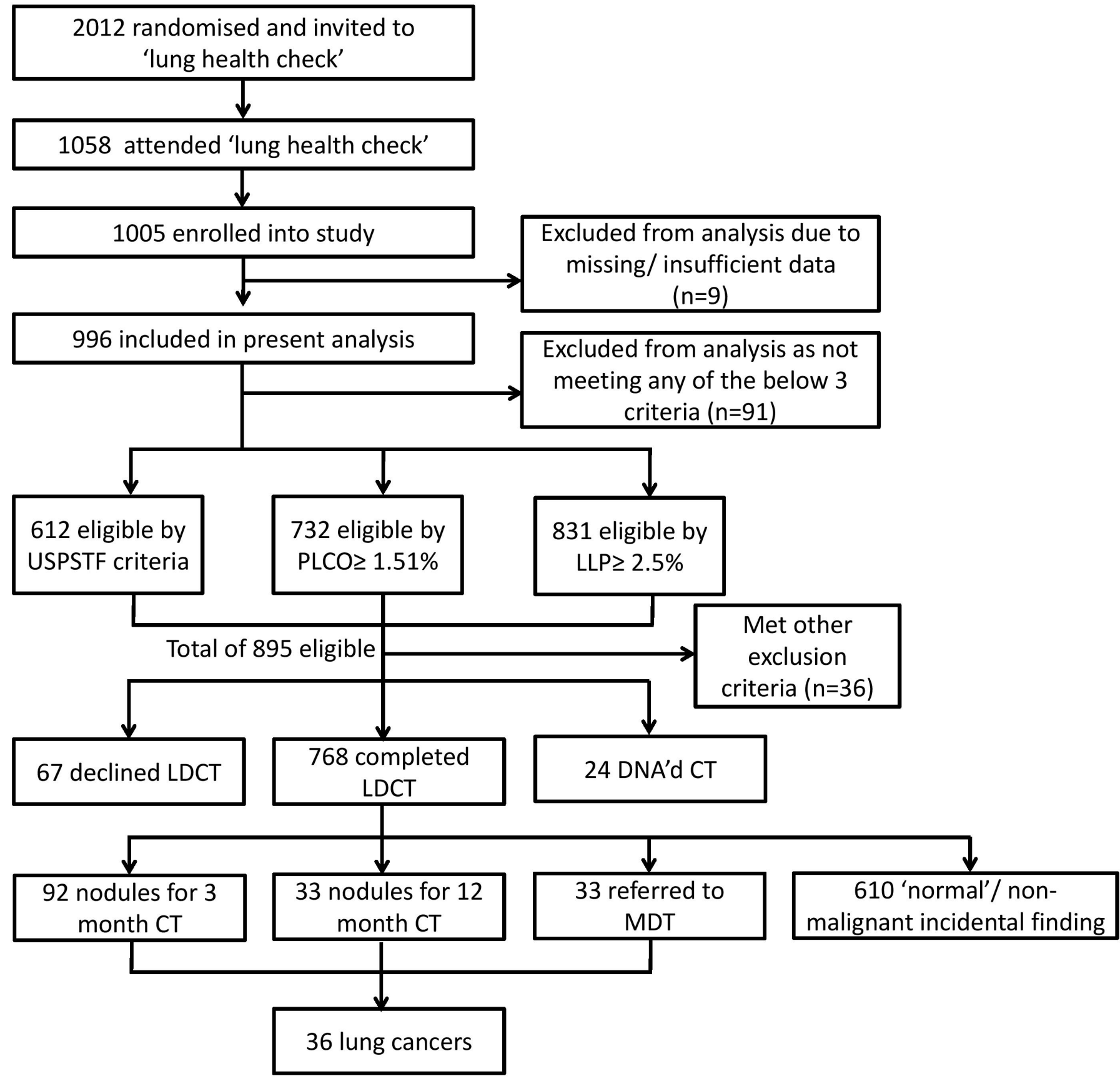

Figure 1 Flow chart of invitees and participants demonstrating numbers identified, invited, enrolled, eligible for LDCT and that completed a LDCT examination. DNA, did not attend; LDCT, low-dose CT; LLP, Liverpool Lung Project; MDT, multidisciplinary team; PLCO ${ }_{\text {m2012, }}$ Prostate, Lung, Colorectal and Ovarianstudy model 2012; USPSFT, United States Preventive Services Task Force.

36 lung cancers (4.7\%) were diagnosed. Of these, 17 (51.5\% of those referred to the lung cancer clinic) were diagnosed directly following the baseline LDCT and the remainder were diagnosed following further surveillance CT scans of indeterminate nodules in the 3 -month ( $\mathrm{n}=16,17.4 \%$ of nodules in this group) or 12-month surveillance groups $(n=3,9.1 \%$ of nodules in this group).

For invasive investigations we report the data as a percentage of the total number of lung cancers (table 2). Forty-nine (136\%) participants underwent positron emission tomography scan, $10(27.8 \%)$ had endobronchial ultrasound and 5 (13.9\%) underwent percutaneous CT-guided lung biopsy. Numbers of diagnostic investigations performed in those without a later diagnosis of cancer are also detailed in table 2. Of note, there were no adverse outcomes from diagnostic investigations in this group. Twenty-one $(58.3 \%)$ participants had a surgical resection without prior histological confirmation of malignancy (and underwent frozen section at the time of the resection), though some had undergone diagnostic staging examinations prior to surgery. 2 out of $28(7.1 \%)$ lung resections were subsequently found to be benign and this represented $0.3 \%$ of participants without lung cancer. There were no deaths within 90 days of surgery.

Twenty-six (72.2\%) of all lung cancers were stage I or II and 27 (79.4\%) of those with non-small cell lung cancer (NSCLC) had curative-intent treatment (including sublobar resection, lobectomy 
Table 1 Participant characteristics by group (\% totals may not sum up due to rounding or missing data)

\begin{tabular}{|c|c|c|c|c|}
\hline Variables & $\begin{array}{l}\text { No LDCT } n=228 \\
\text { median (IQR) or } n(\%)\end{array}$ & $\begin{array}{l}\text { No lung cancer } n=732 \\
\text { median (IQR) or } n(\%)\end{array}$ & $\begin{array}{l}\text { Lung cancers } n=36 \\
\text { median (IQR) or } n(\%)\end{array}$ & $\begin{array}{l}\text { All groups } n=996 \\
\text { median (IQR) or } n(\%)\end{array}$ \\
\hline \multicolumn{5}{|l|}{ Age (in years) } \\
\hline $60-63$ & $86(37.7)$ & $241(32.9)$ & $8(22.2)$ & $335(33.6)$ \\
\hline $64-67$ & $72(31.6)$ & $238(32.5)$ & $11(30.6)$ & $321(32.2)$ \\
\hline $68-72$ & $48(21.1)$ & $158(21.6)$ & $13(36.1)$ & $219(22.0)$ \\
\hline $73-76$ & $22(9.7)$ & $95(13.0)$ & $4(11.1)$ & $121(12.2)$ \\
\hline \multicolumn{5}{|l|}{ Gender } \\
\hline Female & $109(47.8)$ & $317(43.3)$ & $23(63.9)$ & $449(45.1)$ \\
\hline \multicolumn{5}{|l|}{ Ethnicity } \\
\hline White & $183(80.3)$ & $607(82.9)$ & $34(94.4)$ & $824(82.7)$ \\
\hline Black/African/Caribbean & $23(10.1)$ & $77(10.5)$ & $1(2.8)$ & $101(10.1)$ \\
\hline Other & $22(9.7)$ & $48(6.6)$ & $1(2.8)$ & $71(7.1)$ \\
\hline \multicolumn{5}{|l|}{ Highest level of education } \\
\hline Left school at or before age 15 & $105(46.1)$ & $395(54.0)$ & $20(55.6)$ & $520(52.2)$ \\
\hline GCSEs, 0-levels or equivalent & $26(11.4)$ & $75(10.3)$ & $3(8.3)$ & $10410.4)$ \\
\hline A-levels or equivalent & $24(10.5)$ & $70(9.6)$ & $4(11.1)$ & $98(9.8)$ \\
\hline Further education & $14(6.1)$ & $31(4.2)$ & $3(8.3)$ & $48(4.8)$ \\
\hline Bachelor degree & $34(14.9)$ & $84(11.5)$ & $2(5.6)$ & $120(12.1)$ \\
\hline Further higher degree & $20(8.8)$ & $64(8.7)$ & $4(11.1)$ & $88(8.8)$ \\
\hline Other & $5(2.2)$ & $13(1.8)$ & $0(0)$ & $18(1.8)$ \\
\hline \multicolumn{5}{|l|}{ Index of Multiple Deprivation quintile } \\
\hline 1 (most deprived) & $117(51.3)$ & $402(54.9)$ & $19(52.8)$ & $538(54.0)$ \\
\hline 2 & $87(38.2)$ & $245(33.5)$ & $12(33.3)$ & $344(34.5)$ \\
\hline 3 & $3(1.3)$ & $17(2.3)$ & $1(2.8)$ & $21(2.1)$ \\
\hline 4 & $0(0)$ & $2(0.3)$ & $0(0)$ & $2(0.2)$ \\
\hline 5 (least deprived) & $0(0)$ & $0(0)$ & $0(0)$ & $0(0)$ \\
\hline \multicolumn{5}{|l|}{ Smoking history } \\
\hline Current smoker & $148(64.9)$ & $527(72.0)$ & $31(86.1)$ & $706(70.9)$ \\
\hline Years smoked (years) & 42 (33 to 51$)$ & 47 (44 to 51 ) & 51 (47 to 54$)$ & 47 (42 to 51$)$ \\
\hline Years quit (years) & $0(0$ to 3$)$ & $0(0$ to 0$)$ & $0(0$ to 0$)$ & $0(0$ to 0$)$ \\
\hline Average smoking intensity (cigs/day) & 14 (8 to 20$)$ & 20 (10 to 20$)$ & 20 (10 to 23$)$ & $17(10$ to 20$)$ \\
\hline Pack years & 23 (10 to 41$)$ & 38 (26 to 51$)$ & 46 (26 to 63$)$ & $36(21$ to 50$)$ \\
\hline \multicolumn{5}{|l|}{ Lung cancer risk } \\
\hline PLCO (\% 6-year risk) & $1.40(0.39$ to 5.48$)$ & 3.74 (1.80 to 7.14$)$ & 5.68 (2.96 to 9.27$)$ & 3.43 (1.38 to 6.97$)$ \\
\hline LLP (\% 5-year risk) & 3.07 (1.55 to 7.16$)$ & 5.58 (3.79 to 8.75$)$ & 5.5 (4.58 to 9.77$)$ & 5.20 (3.16 to 8.56$)$ \\
\hline \multicolumn{5}{|l|}{ Physical measurements } \\
\hline FEV1 (1/min) & 2.12 (1.68 to 2.57$)$ & 2.06 (1.64 to 2.56$)$ & 1.74 (1.12 to 2.2$)$ & 2.06 (1.64 to 2.55$)$ \\
\hline FEV1 (\% predicted) & 85 (69 to 98$)$ & 82 (66 to 96$)$ & 73 (53 to 89$)$ & 82 (67 to 97$)$ \\
\hline FEV/FVC (\%) & 70 (63 to 77$)$ & $69(61$ to 75$)$ & 62 (54 to 69$)$ & $69(62$ to 76$)$ \\
\hline BMI $\left(\mathrm{kg} / \mathrm{m}^{2}\right)$ & 25.8 (22.9 to 29.1$)$ & 26.2 (23 to 29.4$)$ & 23.5 (22.5 to 26$)$ & $26.0(22.9$ to 29.2$)$ \\
\hline \multicolumn{5}{|l|}{ WHO Performance Status } \\
\hline 0 - asymptomatic & $203(89.0)$ & $660(90.2)$ & $28(77.8)$ & 891 (89.5) \\
\hline 1 - completely ambulatory & $23(10.1)$ & $64(8.7)$ & $8(22.2)$ & $95(9.5)$ \\
\hline $2-<50 \%$ of day in chair/ bed & $1(0.4)$ & $8(1.1)$ & $0(0)$ & $9(0.9)$ \\
\hline $3->50 \%$ of day in chair/ bed & $1(0.4)$ & $0(0)$ & $0(0)$ & $1(0.1)$ \\
\hline \multicolumn{5}{|l|}{ LDCT } \\
\hline Follow-up duration since LDCT (days) & $\mathrm{n} / \mathrm{a}$ & 1007 (851 to 1143$)$ & 1044 (933 to 1153 ) & 1008 (853 to 1144$)$ \\
\hline
\end{tabular}

BMI, body mass index; cigs, cigarettes; CT, Computed Tomography scan; GCSE, General Certificate of Secondary Education; LDCT, low-dose CT; LLP, Liverpool Lung Project; PLCO, Prostate, Lung, Colorectal and Ovarian study; USPSTF, United States Preventive Services Task Force; VATS, Video Assisted Thoracoscopic Surgery. 
Table 2 Investigations rates, and stage, histology and treatments from the baseline LDCT scan

\begin{tabular}{|c|c|c|}
\hline & $\begin{array}{l}\text { Number in total } \\
\text { cohort } \\
\text { (\% of total } \\
\text { lung cancers, } \\
\mathrm{n}=36 \text { (* except } \\
\text { treatments) }\end{array}$ & $\begin{array}{l}\text { Number among } \\
\text { those without a } \\
\text { diagnosis of lung } \\
\text { cancer } \\
\text { (\% of total } \\
\text { participants } \\
\text { without lung } \\
\text { cancer, } n=732 \text { ) }\end{array}$ \\
\hline \multicolumn{3}{|l|}{ Diagnostic or staging investigations } \\
\hline Positron emission tomography (PET) & $49(136)$ & $16(2.2)$ \\
\hline Percutaneous non-lung biopsy & $5(13.9)$ & $0(0)$ \\
\hline Other percutaneous biopsy & $6(16.7)$ & $1(0.1)$ \\
\hline Cervical lymph node FNA & $2(5.6)$ & $0(0)$ \\
\hline Fibreoptic bronchoscopy & $12(33.3)$ & $9(1.2)$ \\
\hline Endobronchial ultrasound & $10(27.8)$ & $1(0.1)$ \\
\hline Endoscopic ultrasound & $1(2.8)$ & $0(0)$ \\
\hline VATS or open lung biopsy & $21(58.3)$ & $2(0.3)$ \\
\hline Total: PET or invasive procedures & & $29(4.0)$ \\
\hline \multicolumn{3}{|l|}{ Histology } \\
\hline Invasive adenocarcinoma & $16(44.4)$ & \\
\hline Minimally invasive adenocarcinoma & $3(8.3)$ & \\
\hline Adenocarcinoma in situ & $1(2.8)$ & \\
\hline Squamous cell carcinoma & $6(16.7)$ & \\
\hline Mixed NSCLC (ie, adenosquamous) & $2(5.6)$ & \\
\hline Small cell lung cancer & $2(5.6)$ & \\
\hline $\begin{array}{l}\text { Multiple or mixed histology (small } \\
\text { cell + NSCLC) }\end{array}$ & $3(8.3)$ & \\
\hline Radiological diagnosis & $2(5.6)$ & \\
\hline Carcinoid & $1(2.8)$ & \\
\hline \multicolumn{3}{|l|}{ Stage (TNM $7^{\text {th }}$ edition) } \\
\hline Stage I \& II & $26(72.2)$ & \\
\hline la & $22(61.1)$ & \\
\hline Ib & $1(2.8)$ & \\
\hline Ila & $3(8.3)$ & \\
\hline Ilb & $0(0)$ & \\
\hline Illa & $6(16.7)$ & \\
\hline IIllb & $1(2.8)$ & \\
\hline IV & $3(8.3)$ & \\
\hline \multicolumn{3}{|c|}{ Treatments (NSCLC) $(* \%$ are of total NSCLC) } \\
\hline Curative intent & $27(79.4)$ & \\
\hline Sub-lobar resection & $11(32.4)$ & \\
\hline Lobectomy & $15(44.1)$ & \\
\hline SABR & $1(2.9)$ & \\
\hline Concurrent chemoradiation & $2(5.9)$ & \\
\hline Palliative chemotherapy \pm radiation & $4(11.8)$ & \\
\hline Surveillance & $1(2.9)$ & \\
\hline \multicolumn{3}{|l|}{$\begin{array}{l}\text { Treatments (SCLC) }(* \% \text { are of total } \\
\text { SCLC) }\end{array}$} \\
\hline Radical chemoradiation & $2(100)$ & \\
\hline
\end{tabular}

Continued
Table 2 Continued

\begin{tabular}{ll}
\hline & $\begin{array}{l}\text { Number among } \\
\text { those without a } \\
\text { diagnosis of lung }\end{array}$ \\
cohort & cancer \\
(\% of total & (\% of total \\
lung cancers, & participants \\
$\mathrm{n}=36$ (*except & without lung \\
treatments) & cancer, $\mathrm{n}=732)$ \\
\hline
\end{tabular}

CT, CT scan; DNA, did not attend; FNA, fine needle aspiration; GCSE, General Certificate of Secondary Education; LDCT, low-dose CT; LHC, lung health check; MDT, multidisciplinary team; NSCLC, non-small cell lung cancer; SABR, stereotactic ablative radiotherapy; SCLC, small cell lung cancer; TNM, tumour, node, metastases; UKLS, United Kingdom Lung Cancer Screening Trial; USPSTF, United States Preventive Services Task Force; VATS, video assisted thorascopic surgery.

and stereotactic ablative radiotherapy). Of the two participants with small cell lung cancer, both received concurrent chemoradiation. Ten (27.8\%) participants had advanced stage (III or IV) disease, resulting in four $(11.8 \%)$ of those with NSCLC undergoing palliative chemotherapy or radiotherapy (table 2). Online supplementary table e1 presents details on all 36 lung cancers.

\section{DISCUSSION}

This observational cohort study demonstrated that despite the very high risk of lung cancer in the cohort, $75.0 \%$ of lung cancers detected were early stage and $79.4 \%$ of the patients with NSCLC had treatment with curative intent. Indeterminate pulmonary nodules for 3-month and 12-month surveillance were detected in $11.9 \%$ and $4.3 \%$ of the participants screened, respectively, and lung cancer was detected in $4.7 \%$.

The rate of indeterminate pulmonary nodules (16.2\%) was lower than in NLST (National Lung Screening Trial; 24.2\%) ${ }^{1}$ and NELSON trial (19.2\%). ${ }^{15}$ This may have been in part due to implementation of the 2015 BTS pulmonary nodule guidelines which enables a more conservative approach to nodules smaller than $5 \mathrm{~mm} .^{9}$ The lung cancer prevalence was significantly higher than the majority of LCS trials, which have reported a $1 \%$ to 2\% prevalence. ${ }^{1617}$ However other higher-risk LCS cohorts have demonstrated a similar lung cancer prevalence to that seen here. ${ }^{618}$ The proportion of participants with early-stage lung cancer who received treatment with curative intent was slightly lower than observed in UKLS, ${ }^{17}$ which again may reflect the population screened. The number of invasive tests for those without a diagnosis of lung cancer was low, with only $4 \%$ of individuals without cancer having a positron emissiontomography-CT (PET-CT) scan or other invasive tests such as bronchoscopy or percutaneous biopsy.

A strength of this study is that it demonstrates a method of recruiting otherwise underserved populations as evidenced by the low socioeconomic and education levels in the majority of the cohort and as such this study illustrates a pragmatic, 'real-world' approach to LCS. It is limited by the small sample size and low number of cancers. We acknowledge that this cohort had particularly high lung cancer risk, however, in light of emerging evidence advocating risk-based selection of LCS-eligible individuals, ${ }^{4}{ }^{19}$ we believe the findings reported here are generalisable to the LCSeligible population.

In conclusion, the rate of indeterminate pulmonary nodules was lower and the rate of lung cancer was higher than previous randomised LCS trials, and one in six individuals with an indeterminate nodule requiring 3-month surveillance LDCT were subsequently diagnosed with lung cancer. From these findings, as well as the impressive early-stage disease and curative intent treatment 
rates observed, we propose that LCS in a 'real-world' setting may be less harmful, more efficient and more cost-effective than has been seen in larger LCS studies.

\author{
Author affiliations \\ 'Lungs for Living Research Centre, UCL Respiratory, University College London, \\ London, UK \\ ${ }^{2}$ Research Department of Behavioural Science and Health, University College London, \\ London, UK \\ ${ }^{3}$ Department of Radiology, University College London Hospitals NHS Foundation \\ Trust, London, UK \\ ${ }^{4}$ Department of Radiology, Homerton University Hospital NHS Foundation Trust, \\ London, UK \\ 5Department of Radiology, Royal Brompton Hospital, London, UK \\ ${ }^{6}$ Killick Street Health Centre, London, UK \\ ${ }^{7}$ Wolfson Institute of Preventive Medicine, Barts and London, London, UK \\ ${ }^{8}$ Thoracic Medicine Department, University College London Hospitals NHS \\ Foundation Trust, London, UK \\ ${ }^{9}$ Respiratory Medicine, Homerton University Hospital NHS Foundation Trust, London, \\ UK \\ ${ }^{10}$ Respiratory Medicine Unit, David Evans Research Centre, Nottingham University \\ Hospitals NHS Trust, Nottingham, UK
}

\section{Twitter Mamta Ruparel @mamta_ruparel and Arjun Nair @LUNGRADIOLOGIST}

Contributors All authors were involved in the design and/or conduct of the study or the interpretation of the results. All authors contributed to and approved the final manuscript.

Funding This study was part of the Lung Screen Uptake Trial project, which was funded by a National Awareness and Early Diagnosis Initiative (NAEDI) project grant awarded by Cancer Research UK (CRUK) and a consortium of funders (Department of Health (England); Economic and Social Research Council; Health and Social Care R\&D Division, Public Health Agency, Northern Ireland; National Institute for Social Care and Health Research, Wales; Scottish Government) (SLQ and SMJ). SMJ is a Wellcome Trust Senior Fellow in Clinical Science (WT107963AIA). SMJ is supported by the Rosetrees Trust, the Roy Castle Lung Cancer Foundation, the Stoneygate Trust, the Welton Trust, the Garfield Weston Trust and the UCLH Charitable Foundation. This work was undertaken at UCLH/UCL who received a proportion of funding from the Department of Health's NIHR Biomedical Research Centre's funding scheme (NN and SMJ). SLQ is supported by a CRUK Postdoctoral Fellowship (C50664/A24460).

Competing interests SMJ, MR, JLD, CH, ST and HH are supported by funding for a large trial of low dose CT screening, called the 'SUMMIT Study' by GRAIL Inc. SLQ and NN collaborate on the SUMMIT Study. SMJ has received honoraria from AstraZeneca, BARD1 Bioscience and Janssen for being an Advisory Board Expert and travel to a US conference. SMJ received grant funding from Owlstone for a separate research study and has a family member who has a financial association with AstraZeneca. MR has received travel funding for a conference from Takeda and an honorarium for planning and speaking at educational meetings from AstraZeneca.

Patient consent for publication Not required.

Ethics approval This study is part of the Lung Screen Uptake Trial (LSUT), which was granted ethical approval by the City Road and Hampstead NHS Research Ethics Committee (REC; reference: 15/LO/1186) and was registered with ClinicalTrials.gov (NCT02558101) and the International Standard Registered Clinical/soCial sTudy Number (ISRCTN21774741)

Provenance and peer review Not commissioned; externally peer reviewed.

Open access This is an open access article distributed in accordance with the Creative Commons Attribution 4.0 Unported (CC BY 4.0) license, which permits others to copy, redistribute, remix, transform and build upon this work for any purpose, provided the original work is properly cited, a link to the licence is given, and indication of whether changes were made. See: https://creativecommons.org/ licenses/by/4.0/.

\section{ORCID iDs}

Mamta Ruparel http://orcid.org/0000-0001-8880-6567

Carolyn Horst http://orcid.org/0000-0003-2427-6610

Neal Navani http://orcid.org/0000-0002-6412-7516

Sam M Janes http://orcid.org/0000-0002-6634-5939

\section{REFERENCES}

1 National Lung Screening Trial Research Team, Aberle DR, Adams AM, et al. Reduced lung-cancer mortality with low-dose computed tomographic screening. N Engl J Med 2011;365:395-409.

2 de Koning $\mathrm{HJ}$, van der Aalst CM, de Jong PA, et al. Reduced lung-cancer mortality with volume CT screening in a randomized trial. N Engl J Med 2020;382:503-13.

3 Pastorino U, Silva M, Sestini S, et al. Prolonged lung cancer screening reduced 10-year mortality in the mild trial: new confirmation of lung cancer screening efficacy. Ann Oncol 2019;30:1162-9.

4 Kovalchik SA, Tammemagi M, Berg CD, et al. Targeting of low-dose CT screening according to the risk of lung-cancer death. N Engl J Med 2013;369:245-54.

5 Black WC, Gareen IF, Soneji SS, et al. Cost-effectiveness of CT screening in the National lung screening trial. N Engl J Med Overseas Ed 2014;371:1793-802.

6 Crosbie PA, Balata H, Evison M, et al. Implementing lung cancer screening: baseline results from a community-based 'Lung Health Check' pilot in deprived areas of Manchester. Thorax 2019;74:405-9.

7 Quaife SL, Ruparel M, Beeken RJ, et al. The Lung Screen Uptake Trial (LSUT): protocol for a randomised controlled demonstration lung cancer screening pilot testing a targeted invitation strategy for high risk and 'hard-to-reach' patients. BMC Cancer 2016;16:281.

8 Quaife SL, Ruparel M, Dickson JL, et al. Lung screen uptake trial (LSUT): randomized controlled clinical trial testing targeted invitation materials. Am J Respir Crit Care Med 2020;201:965-75.

9 Guideline Development Group. The British thoracic Society guidelines on the investigation and management of pulmonary nodules. Thorax 2015;70:794-8.

10 Baldwin DR, White B, Schmidt-Hansen M, et al. Diagnosis and treatment of lung cancer: summary of updated NICE guidance. BMJ 2011;342:d2110.

11 Ruparel M, Quaife SL, Dickson JL, et al. Evaluation of cardiovascular risk in a lung cancer screening cohort. Thorax 2019;74:1140-6.

12 Ruparel M, Quaife SL, Dickson JL. Prevalence, symptom burden and under-diagnosis of COPD in a lung cancer screening cohort, 2019. Available: www.atsjournals.org [Accessed 7 Jun 2019].

13 Ruparel M, Quaife SL, Dickson JL, et al. Prevalence, symptom burden, and underdiagnosis of chronic obstructive pulmonary disease in a lung cancer screening cohort. Ann Am Thorac Soc 2020;17:869-78.

14 Ruparel M, Quaife SL, Dickson JL, et al. Is lung cancer screening an opportunity to reduce cardiovascular mortality? 2019;259:A5896.

15 Horeweg N, van der Aalst CM, Vliegenthart R, et al. Volumetric computed tomography screening for lung cancer: three rounds of the Nelson trial. Eur Respir J 2013:42:1659-67.

16 Horeweg N, van Rosmalen J, Heuvelmans MA, et al. Lung cancer probability in patients with CT-detected pulmonary nodules: a prespecified analysis of data from the Nelson trial of low-dose CT screening. Lancet Oncol 2014;15:1332-41.

17 Field JK, Duffy SW, Baldwin DR, et al. UK lung cancer RCT pilot screening trial: baseline findings from the screening arm provide evidence for the potentia implementation of lung cancer screening. Thorax 2016;71:161-70.

18 Bechtel JJ, Kelley WA, Coons TA, et al. Lung cancer detection in patients with airflow obstruction identified in a primary care outpatient practice. Chest 2005;127:1140-5.

19 Ten Haaf K, Tammemägi MC, Bondy SJ, et al. Performance and cost-effectiveness of computed tomography lung cancer screening scenarios in a population-based setting: a Microsimulation modeling analysis in Ontario, Canada. PLoS Med 2017:14:e1002225. 